\title{
AS TEIAS QUE A FAMÍLIA TECE: UMA REFLEXÃO SOBRE O PERCURSO DA HISTÓRIA DA FAMÍLIA NO BRASIL
}

\author{
The Family Web: the trajectory of \\ Family History in Brazil
}

Ana Silvia Volpi Scott*

\begin{abstract}
RESUMO
Este artigo apresenta uma reflexão sobre a trajetória dos estudos sobre a família no Brasil, chamando a atenção para as tendências mais recentes que procuram não só reavaliar conceitos como o patriarcalismo, mas incorporam outras ferramentas conceituais como a noção de estratégia familiar ou rede social. A partir da contribuição dos trabalhos clássicos sobre a família, passando pela produção vinculada à demografia histórica e história da população, procura-se analisar alguns estudos produzidos nos últimos cinco anos que, usando o cruzamento de fontes e a microanálise, produzem novos e ricos olhares para este universo multifacetado que é a família.
\end{abstract}

Palavras-chave: família; fontes; metodologia.

\begin{abstract}
The main purpose of this article is to present an overview about the recent tendencies on Family History in Brazil, analyzing some classical concepts as patriarcalism, or other concepts as family strategies or social network. Special attention was given to studies in the area of Historical Demography and Population History, mostly linked to the books published in the last five years using record linkage and microanalysis background.
\end{abstract}

Keywords: family; sources; methodology.

* Professora Adjunta II do Programa de Pós-Graduação em História da Universidade do Vale do Rio dos Sinos (Unisinos), Pesquisadora do CNPq. E-mail: asilvia@unisinos.br. 
O estudo da família tem atraído cada vez mais a atenção de especialistas de diferentes áreas. No campo da história, as análises sobre esta instituição têm crescido de maneira espetacular, tanto no Brasil como no exterior, e os inúmeros trabalhos que vêm a público têm contribuído de forma decisiva para o debate. Neste contexto de intensas discussões sobre a temática da família, a proposta da História: Questões e Debates de organizar um volume especial sobre esse tema constitui mais um espaço privilegiado para a reflexão. Certamente os grandes beneficiados serão os pesquisadores preocupados com o estudo do universo familiar numa sociedade multifacetada e heterogênea como é a brasileira.

Nas últimas quatro décadas, o crescimento do estudo da família entre os historiadores brasileiros veio, em grande parte, dos trabalhos produzidos no âmbito de Demografia Histórica. Contudo, os estudos sobre a família se alargaram de tal maneira, principalmente por conta do diálogo com as Ciências Sociais, que as recentes pesquisas não se limitam apenas ao estudo do aspecto demográfico, embora este continue a fornecer elementos importantes para a compreensão da organização e das dinâmicas familiares.

Essa abertura a outras áreas se justifica pela complexidade do tema, pois a compreensão dos sistemas familiares do passado não pode limitar-se ao estudo das variáveis demográficas ou dos critérios de corresidência, por conta das múltiplas situações de vida que são contempladas pela família como instituição básica de praticamente todas as sociedades.

A ampliação desse universo para além do núcleo constituído por pais e filhos e/ou corresidentes, englobando a parentela, ganhou cada vez mais atenção dos estudiosos a partir do diálogo interdisciplinar, sobretudo com a Antropologia e a Sociologia.

Também foi fundamental a contribuição teórico-metodológica advinda da micro-história e da proposta da redução da escala de abordagem, que procura fazer sobressair o comportamento social dos atores históricos.

A observação possibilitada através dos jogos de escala permitiu avançar nas discussões relativas às estratégias familiares e às redes sociais para as sociedades do passado. Essa perspectiva apresenta-se como um campo rico de investigação, especialmente se admitirmos que toda ação social é o resultado de escolhas, de decisões do indivíduo e do grupo familiar; por isso mesmo, implica numa constante negociação e, por que não dizer, manipulação, diante de uma realidade normativa que oferece muitas possibilidades de interpretações e liberdades pessoais. 
Se estivermos de acordo com esta afirmação, uma questão de relevo para o historiador da família passa a ser a análise das escolhas e das estratégias de manobra que são utilizadas pelos indivíduos e famílias para lidar com os sistemas normativos existentes, aproveitando-se de suas brechas e/ou contradições. Nesse contexto, emerge a questão das redes familiares e sociais - que é uma contribuição conceitual fundamental para a análise do universo familiar, especialmente quando se opta pela redução da escala de abordagem.

A combinação desses dois elementos é enriquecedora também quando o historiador que se preocupa com os estudos das estratégias familiares e das redes sociais se vale do recurso do cruzamento de fontes laicas e eclesiásticas. Desta maneira, estão reunidos os elementos fundamentais para o estudo dessas redes, constituídas através dos vínculos de consanguinidade, aliança ou afinidade, bem como a partir de relações de outra natureza, como os vínculos de subordinação e/ou dependência.

Essa é uma vertente que tem recebido a atenção dos historiadores e, na última década, alguns trabalhos que vieram a público ilustram com muita clareza os caminhos mais recentes que a historiografia sobre a família tem percorrido no início do século XXI.

Porém, antes de analisar essa produção mais recente, é oportuno recuperar essa trajetória que teve início há quase cinco décadas, quando a Demografia Histórica entrou definitivamente na pauta de discussão dos historiadores no Brasil.

A demografia histórica deu - e continua a dar - um aporte fundamental para o desenvolvimento da História da Família no Brasil. A expansão das áreas analisadas e a multiplicação dos estudos que têm vindo a público dão a medida da riqueza e da variedade das fontes utilizadas, o que é um traço comum dos trabalhos que se dedicam ao tema, não só no caso brasileiro, como também na América Latina ${ }^{1}$.

1 Uma referência fundamental que sublinha a diversidade e a riqueza das fontes mais comumente utilizadas nos estudos sobre a família em perspectiva histórica é a obra organizada por Pablo Rodríguez e Annie Molinie-Bertrand (Eds.). A través del tiempo. Diccionario de fuentes para la historia de la familia. Murcia: Universidad de Murcia, 2000. Especificamente sobre as fontes utilizadas para o estudo da família como categoria demográfica para a América Latina, encontramos dados de interesse recentemente publicados em Cuba: BENÍTEZ PÉREZ, M. E.; ALFONSO DE ARMAS, M. La familia como categoría demográfica. In: ESTRADA, A. V. (Ed.). La familia y las Ciencias Sociales. La Habana: Centro de Investigación y Desarollo de la Cultura Cubana Juan Marinello, 2003, p. 162-194. Referimos também as informações sobre as fontes, 
Entre outras contribuições, os trabalhos produzidos apontaram a extrema variação da organização familiar latino-americana e brasileira, impondo a utilização do termo "famílias", no plural, porque são inúmeras as possibilidades de arranjos familiares que, por sua vez, também variaram no tempo, no espaço e de acordo com os distintos grupos sociais.

Uma avaliação sobre a contribuição dos estudos de caráter demográfico para os avanços dos estudos sobre a família no caso do Brasil foi apresentada em artigo que discutiu os quarenta anos da introdução da Demografia Histórica no país².

O balanço produzido depois dessas quatro décadas revelou que os estudiosos da família valeram-se das metodologias provenientes da escola francesa e da escola inglesa e, mais recentemente, das metodologias inspiradas na micro-história italiana, com os seguimentos nominativos. Destacou ainda que muito do que havia sido produzido em termos de história da família estava baseado na exploração de duas séries documentais principais: os registros paroquiais e as listas nominativas de habitantes, também conhecidas como Maços de População.

Deve-se sublinhar, além disso, que uma parcela significativa dos estudos sobre a história da família concentra-se entre a segunda metade do século XVIII e a primeira metade do XIX e esse fato está diretamente vinculado à existência das fontes primárias utilizadas, como os maços de população, concentrados, grosso modo, entre 1765 e 1850, e a disponibilidade dos registros paroquiais, fonte que apresenta lacunas e limites de abrangência temporal. No caso da documentação paroquial, é fato notório que para os primeiros séculos da colonização poucas séries de assentos vitais sobreviveram até nossos dias. Esta triste realidade deve-se a diversos fatores ligados, por um lado, às condições precárias e inadequadas de conservação dos documentos, e, por outro, como resultado direto da marcha da ocupação e integração do espaço americano sob domínio luso na América, que se caracterizou pelo constante desmembramento territorial e reorganização da administração laica e eclesiástica. A cada nova criação

disponibilizadas na obra de José Luiz Moreno. Nesta mesma obra, encontra-se um ensaio bibliográfico que faz uma útil resenha dos principais trabalhos sobre a história da família na América Latina: História de la família en el Rio de la Plata. Buenos Aires: Sudamericana, 2004, p. 283-313.

2 BACELLAR, C. A. P.; SCOTT, A. S. V. et al. Quarenta anos de Demografia Histórica. Revista Brasileira de Estudos de População, v. 22, n. 2, p. 339-350, 2005. 
de diocese, remanejavam-se os documentos para a nova sede, acarretando em perda e desorganização dos fundos documentais ${ }^{3}$.

Com relação às listas nominativas de habitantes, sua riqueza é conhecida entre os pesquisadores da família. É uma documentação de caráter seriado, que organizava a população em fogos ou domicílios, isto é, arrolava e sistematizava todos os indivíduos de uma dada vila segundo critérios de corresidência. A sua utilização pelos historiadores contribuiu para a disseminação dos métodos produzidos pelo Grupo de Cambridge, a partir de uma tipologia de classificação dos domicílios. Além disso, serviu de base para uma adaptação da metodologia francesa de reconstituição de famílias proposta por Maria Luiza Marcílio e aplicada em dois estudos sobre a Capitania-Província de São Paulo ${ }^{4}$.

Contudo, se o boom de estudos sobre a família se deu a partir da década de 1980, sobretudo com ênfase nas metodologias da demografia histórica, não se deve esquecer as contribuições fundamentais dadas ao estudo da família no Brasil, que remontam às primeiras décadas do século $\mathrm{XX}$, destacando-se os estudos pioneiros de Oliveira Viana e Gilberto Freyre.

Naquela oportunidade, a temática da família havia sido tratada de forma diferente e a preocupação central estava voltada para examinar a família e a sua relação com o Estado, procurando entender o processo de formação da nação no Brasil. Nesse contexto, os estudos de Gilberto Freyre sublinhavam o perfil patriarcal da família brasileira - que se tornaram clássicos da literatura nacional e internacional ${ }^{5}$. Também inserida nessa vertente está a contribuição de Oliveira Vianna, no livro Populações Meridionais, ao

3 COSTA, I. D. N. Registros paroquiais: notas sobre os assentos de batismo, casamento e óbito. Revista de História, v. 1, n. 1, p. 46-54, 1990; MARCÍLIO, M. L. Os registros paroquiais e a História do Brasil. Varia História, n. 31, p. 13-20, 2004.

4 SCOTT, A. S. V. Dinâmica familiar da elite paulista (1765-1836). Dissertação (Mestrado) - Universidade de São Paulo, 1987; SCOTT, A. S. V. Família, casa e fortuna: os grandes proprietários de escravos em São Paulo (1765-1836). Boletín de la Asociación de Demografía Histórica, v. 13, n. 2, p. 91 139, 1995; BACELLAR, C. D. A. P. Senhores da Terra: família e sistema sucessório entre os senhores de engenho do oeste paulista (1765-1855). Campinas: Centro de Memória - UNICAMP, 1997.

5 A família de tipo patriarcal pode ser definida como um grupo complexo e numeroso, que congregava o senhor - todo-poderoso - e sua esposa, seus filhos, noras, genros e netos, aos quais se adicionavam parentes, afilhados, concubinas, filhos ilegítimos e agregados, acompanhados pela escravaria e circundados pelos vizinhos e amigos. Ver MOTTA, J. F. The Historical Demography of Brazil at the V Centenary of its discovery. Ciencia e Cultura. Journal of the Brazilian Association for the Advancement of Science, v. 51, n. 5/6, p. 446-456, 1999. Voltaremos a esta questão. 
utilizar a noção de clã parental para estudar a família senhorial e a formação da sociedade brasileira ${ }^{6}$.

Os ensaios sobre a família produzidos por esses autores não podiam desvincular-se das especificidades de nossa sociedade, marcada pelo escravismo e pelo patriarcalismo. Gilberto Freyre, em Casa Grande \& Senzala, primeira edição do ano de $1933^{7}$, colocou a família no centro do debate, pois era considerada a base da estruturação da sociedade colonial. Na sua perspectiva, era a família - e não o indivíduo ou o Estado - o verdadeiro fator colonizador do Brasil, exercendo a justiça, controlando a política, produzindo riquezas, ampliando territórios e imprimindo o ritmo da vida religiosa, como recordou Sheila Faria ${ }^{8}$.

Caio Prado Júnior também é um nome a ser lembrado e sua análise incidia sobre as questões da instabilidade, do desregramento e da promiscuidade, que seriam as características marcantes da sociedade colonial, incluindo as famílias das casas-grandes, reflexões contidas no clássico livro Formação do Brasil Contemporâneo, publicado originalmente em $1942^{9}$.

Sérgio Buarque de Holanda também deu sua contribuição à discussão no livro Raízes do Brasil, apontando a importância do pater-familias na empresa colonial, sublinhando que a família patriarcal e latifundiária não pretendia formar cidadãos e, sim, parentes, propiciando a invasão do público pelo privado, do Estado pela família ${ }^{10}$.

A temática continuou a receber atenção crescente de outros estudiosos nas décadas de 1950 e 1960, por intermédio da incorporação de inúmeros intelectuais que escreveram sobre a organização e a estrutura da família brasileira, dando ênfase à questão do poder e das parentelas, buscando as bases patriarcais da sociedade brasileira ${ }^{11}$.

6 VIANNA, O. Populações Meridionais do Brasil. Rio de Janeiro: Paz e Terra, 1973. Primeiro livro publicado pelo autor, em 1920.

7 FREYRE, G. Casa Grande \& Senzala: formação da família brasileira sob o regime patriarcal. Rio de Janeiro: José Olympio, 1981.

8 FARIA, S. C. Família. In: VAINFAS, R. (Ed.). Dicionário do Brasil Colonial (1500-1808). Rio de Janeiro: Objetiva, 2000.

9 PRADO JÚNIOR, C. Formação do Brasil Contemporâneo. São Paulo: Brasiliense, 1977.

10 MUAZE, M. A. F. O Império do Retrato: família, riqueza e representação social no Brasil oitocentista (1840-1889). Tese (Doutorado) - Centro de Estudos Gerais/Instituto de Ciências Humanas e Filosofia, Universidade Federal Fluminense, Niterói, 2006, p. 12-13.

11 Destacam-se nomes como Antonio Cândido de Mello e Souza, Emílio Willems, Donald Pierson, Oracy Nogueira, Thales de Azevedo, Charles Wagley, entre outros. 
Contudo, foi o avanço da História Social, na década de 1970, que trouxe novo fôlego para o estudo da família, caracterizando-se pela diversificação temática, quando as pesquisas passaram a incorporar análises sobre a condição feminina, a criança, a ilegitimidade, o casamento, o concubinato e a transmissão de fortunas.

A destacar ainda, na década de 1980, que o estudo da família negra surgiu com mais força, ligado à reflexão sobre a questão escravista - não podemos esquecer que em 1988 completava-se um século da abolição da escravidão no Brasil. No mesmo contexto, afloraram temas até então praticamente inexplorados ou considerados de menor importância nas épocas anteriores. Contudo, nos limites deste artigo não é possível avançar para a discussão específica sobre o tema da escravidão e da contribuição dos estudos da Demografia Histórica e da História da Família neste campo. No entanto, é importante destacar a polêmica gerada na década de 1990, a partir das críticas de Jacob Gorender a este tipo de estudos ${ }^{12}$, bem como as contribuições mais recentes de Manolo Florentino, Robert Slenes, José Flavio Motta, entre tantos outros.

Especificamente sobre o período colonial e sobre a contribuição da historiografia nos inícios dos anos de 1990, Maria Beatriz Nizza da Silva sublinhava que, ainda naquele momento, as pesquisas concentravam-se na História Social, prolongando-se na História da Família, na História da Mulher, na Demografia Histórica e na área denominada em alguns países como História das Mentalidades. Afirmava ainda que os grupos sociais, enquanto objeto da História Social, tinham ocupado relativamente pouco os historiadores brasileiros: a historiografia norte-americana (os chamados brazilianistas $)^{13}$ havia dado sua contribuição em relação ao grupo mercantil, os senhores de engenho teriam merecido a atenção da historiografia (até por encarnar o papel de dominadores na sociedade colonial), enquanto que as camadas mais pobres da população só muito recentemente vinham merecen-

12 Veja-se, por exemplo, GORENDER, J. A escravidão colonial. São Paulo: Ática, 1978. Mais recentemente, alguns balanços sobre os estudos sobre a escravidão podem ser encontrados em MOTTA, J. F. Corpos escravos, vontades livres. Estrutura da posse de cativos e familia escrava em Bananal (18011829). São Paulo: FAPESP/Annablume, 1999, e em SCHWARTZ, S. Escravos, roceiros e rebeldes. Bauru (SP): EDUSC, 2001.

13 Os Brazilianistas tiveram um papel fundamental no avanço dos estudos sobre a família no passado brasileiro. Caberia até mesmo uma reflexão específica sobre estes trabalhos, que não pode ser feita aqui. No entanto, devemos lembrar os trabalhos de Donald Ramos, Elizabeth Kuznesof, Alida Metcalf, Muriel Nazzari, Darryl Levi, Linda Lewin, entre tantos outros. 
do a atenção dos pesquisadores. Notava ainda que a temática da escravidão (africana e indígena) também vinha sendo abordada pelos estudiosos ${ }^{14}$.

No final da mesma década, e a propósito do V Centenário do Descobrimento, José Flávio Motta chamava a atenção para as questões de fundo que ainda preocupavam os estudiosos: a inexistência de um consenso em torno da definição de família, relacionado tanto à questão do patriarcalismo como às dificuldades inerentes às diferentes categorizações utilizadas ${ }^{15}$.

Outra vertente que se consolidou nos últimos anos, tanto no Brasil, como no âmbito latino-americano, aponta para a necessidade de se aprofundar o estudo relativo às diferenças e às especificidades das famílias no contexto da América Latina quando comparada à matriz europeia.

Os resultados sobre a América Latina sublinham que proliferavam as uniões baseadas no concubinato, que as taxas de ilegitimidade apresentavam altos percentuais e que proporções significativas de domicílios eram chefiados por mulheres. Por isso, a historiografia sobre a família na América Latina, desde inícios da década de 1990, vem reforçando a especificidade da sociedade colonial que se construiu nos territórios americanos dominados pelas coroas ibéricas ${ }^{16}$.

O mundo que se forjou na América sob o domínio ibérico, profundamente heterogêneo e miscigenado, punha em evidência suas diferenças em relação aos padrões familiares propostos com base nos estudos sobre as sociedades do Noroeste Europeu. Além disso, tais padrões instituíram-se como parâmetro analítico para as sociedades americanas, e por isso mesmo reforçavam a ideia de "originalidade" ou até mesmo a "anormalidade" da família latino-americana no passado colonia ${ }^{17}$.

Nessa mesma linha, e em artigo publicado há dez anos, também procuramos apontar as contribuições da demografia histórica para o estudo

14 SILVA, M. B. N. Guia de História do Brasil Colonial, v. 2. Porto: Universidade Portucalense/ Infante D. Henrique, 1992, p. 7-12. Os trabalhos de Maria Beatriz Nizza da Silva são contribuições essenciais para o estudo da família no Brasil há pelo menos duas décadas e dispensam maiores comentários.

15 MOTTA, J. F. The Historical Demography of Brazil at the V Centenary of its discovery. Ciência e Cultura. Journal of the Brazilian Association for the Advancement of Science, v. 51, n. 5/6, p. 446-456, 1999.

16 GONZALBO AIZPURU, P. (Ed.). Familias Novohispanas. Siglos XVI al XIX. México, D.F.: El Colegio de México Ed., 1991; McCAA, R. Female and Family in Nineteenth-Century Latin America. Journal of Family History, v. 16, n. 3, 1991; MARCÍLIO, M. L. (Ed.). Familia, mulher, sexualidade e Igreja na História do Brasil. São Paulo: CEDHAL-CEHILA/Edições Loyola, 1993.

17 McCAA, R. E. Introduction. Journal of Family History, v. 16, n. 3, p. 211-214, 1991. 
da história da família. Buscamos ressaltar a importância de se considerar os avanços dos estudos sobre a família em Portugal para compreender melhor a influência e as adaptações que a matriz familiar lusitana teria tido nos territórios coloniais americanos, além de procurar relativizar a "originalidade" da organização familiar americana, pelo menos em comparação com a região noroeste de Portugal $^{18}$.

É urgente que se estimule essa discussão numa dimensão comparativa, como sublinhou Ana Vera Estrada. Para tratar a grande diversidade das formas familiares, é necessário recorrer a modelos que facilitem as comparações, que acelerem ou renovem a utilização de recursos técnicos e metodológicos. Isto, sem dúvida, favorecerá as contínuas descobertas sobre o rico e variado universo familiar da história da América Latina, estimulando o profícuo diálogo que se estabelece entre a história e as ciências sociais ${ }^{19}$.

Contudo, talvez um traço mais importante a ser sublinhado seja a importância que a questão do patriarcalismo continua a ter entre os historiadores que tratam a temática da família, debate que, com altos e baixos, se mantém na pauta das discussões desde os trabalhos clássicos de Gilberto Freyre. Nesse sentido, a análise da família no passado brasileiro não pode prescindir de uma reflexão sobre essa questão.

Ao refletirmos sobre a trajetória dos estudos sobre a família no Brasil, verificamos que entre as décadas de 1980 e 1990 temos um dos momentos de intenso debate sobre o patriarcalismo. Naquela oportunidade houve uma polarização entre a historiografia tradicional, que defendia o predomínio da "família patriarcal" (vinculada aos nomes de Gilberto Freyre, Sérgio Buarque de Holanda, Antonio Cândido de Mello e Souza) e aqueles que ressaltavam a obsolescência do modelo patriarcal enquanto elemento de compreensão do "passado familiar" brasileiro. Nesse sentido, são interessantes as reflexões de Ronaldo Vainfas ${ }^{20}$.

Para Vainfas, a questão polêmica girou em torno da crítica ao "estereótipo" da família numerosa, composta não só pelo núcleo conjugal e seus filhos, mas de uma vasta gama de criados, parentes, agregados e escravos

18 SCOTT, A. S. V. A contribuição da Demografia Histórica para a História da População e da Família no Brasil. Boletín de la Asociación de Demografía Histórica, v. XVI, n. 1, p. 297-353, 1998.

19 ESTRADA, A. V. (Ed.). La familia y las Ciencias Sociales. La Habana: Centro de Investigación y Desarrollo de la cultura Cubana Juan Marinello, 2003, p. 9-10.

20 VAINFAS, R. Trópico dos Pecados: moral, sexualidade e Inquisição no Brasil. Rio de Janeiro: Campus. 1989, p. 107-113. 
submetidos ao poder quase absoluto do chefe da casa. Este, a um só tempo, marido, pai e patriarca, verdadeiro dominus da casa-grande ${ }^{21}$.

A questão que emergia desta polêmica trazida por Vainfas e retomada por outros autores se resumia numa afirmação importante:

Se as famílias coloniais eram mais ou menos extensas, se numa dada habitação moravam pouco indivíduos ou dezenas deles, eis um dilema de pouca relevância nos trabalhos de Freyre e Cândido. E quer-nos parecer, ainda, que a maior ou menor concentração de indivíduos, fosse em solares, fosse em casebres, em nada ofuscava o patriarcalismo dominante, a menos que se pretenda que, pelo simples fato de não habitarem a casa-grande, as assim chamadas "famílias alternativas" viviam alheias ao poder e aos valores patriarcais, o que ninguém seria capaz de afirmar, seguramente ${ }^{22}$.

A temática continuou na pauta das discussões nos inícios do século XXI e esse debate continua a estimular a reflexão entre os historiadores e vem aparecendo em numerosos trabalhos, como os de Bart Barickman, Cacilda Machado e Silvia Brügger ${ }^{23}$.

Bart J. Barickman, na abertura do referido artigo, retoma a discussão a propósito de Gilberto Freyre, sublinhando que o sociólogo era o saco de pancadas predileto entre os estudiosos interessados na história da família no Brasil colonial e do século XIX, afirmando que

[...] a descrição pode, ou não, ser justa e correta. Mas, se é correta, apenas serve para indicar a enorme influência que os argumentos de Freyre têm exercido sobre a historiografia. Efetivamente, Casa Grande \& Senzala e outros livros do sociólogo pernambucano são ainda hoje referências fundamentais para as pesquisas, não só sobre a história da família, como também sobre uma ampla variedade de questões históricas no Brasil.

21 VAINFAS, op. cit., p. 107.

22 Ibidem, p. 110.

23 BARICKMAN, B. J. E se a casa-grande não fosse tão grande? Uma freguesia açucareira do Recôncavo Baiano em 1835. Afro-Ásia, v. 29/30, p. 79-132, 2003; MACHADO, C. O patriarcalismo possível: relações de poder em uma região do Brasil escravista em que o trabalho familiar era a norma. Revista Brasileira de Estudos de População, v. 23, n. 1, p. 167-186, 2006; BRÜGGER, S. M. J. Minas patriarcal: família e sociedade. São Paulo: Annablume, 2007. 
Barickman retoma o debate indicando os pontos fracos dessa literatura revisionista. Em primeiro lugar, o fato de que a maioria dos estudos concentrou-se numa área geográfica que abrange São Paulo e Minas Gerais, sendo raros os trabalhos que utilizaram a mesma documentação para investigar outras regiões, sobretudo o Nordeste. A consequência direta foi o parco conhecimento sobre as estruturas domésticas numa região vasta e variada que, no início XIX, abrigava quase metade da população brasileira. Como resultado, as pesquisas revisionistas poderiam, no máximo, refutar de modo indireto a visão tradicional da casa-grande patriarcal que se associa a Freyre ${ }^{24}$.

Segundo, e mais importante, na mesma linha defendida por Ronaldo Vainfas, chama a atenção para a confusão conceitual entre a "família patriarcal" e a "família extensa", que muitas vezes caracterizava a literatura revisionista - que tinha como fonte principal os censos nominativos.

Porém, como salientam esses autores, o conceito de patriarcalismo pouco ou nada tem a ver com a presença de noras, genros, netos, filhos casados, sobrinhos e outros parentes como moradores da unidade doméstica. Antes, é um conceito que remete, sobretudo, ao poder pátrio, à autoridade dada aos pais e aos maridos, como pais e maridos (grifo de Barickmam), sobre seus filhos e esposas ${ }^{25}$.

Isso gerou inclusive conclusões contraditórias sobre a família no Brasil, quando uns defendem que a estrutura extensa foi um dos traços mais característicos da "família brasileira" enquanto outros "provam" que a família brasileira é e sempre foi restrita à unidade nuclear.

Essa contradição, segundo Barickman, de fato não existe, uma vez que as conclusões conflitantes decorrem, em grande medida, de definições diferentes de família: por um lado, a família como uma rede de parentesco, ou seja, como parentela; por outro, a família como grupo doméstico censitário, isto é, conforme o caso, um fogo ou domicílio. As contradições começam a se desfazer assim que se leva em conta a distinção entre as duas definições de familita $^{26}$.

Conforme a sua argumentação, a raiz deste problema reside no fato de que Freyre não se deu ao trabalho de definir o seu conceito de família

24 BARICKMAN, op. cit., p. 83-85.

25 Ibidem, p. 121.

26 Idem. 
patriarcal, nem mesmo definiu o que entendia por família, muito embora se possa assumir a identificação entre casa e família. Barickman, contudo, sugere que Freyre poderia ter usado o conceito de patriarcalismo em mais de um sentido e entendido "família" como um grupo doméstico que compartilhava a mesma habitação e, ao mesmo tempo, como uma rede de parentesco com mais de uma unidade doméstica ${ }^{27}$.

Eis aí, a nosso ver, o ponto central que nos últimos anos vem animando os estudos sobre a família no Brasil: não só ampliar a abrangência geográfica e temporal, como se valer de um leque de fontes muito mais alargado e, sobretudo, investir no aprofundamento da discussão conceitual, assim como ampliar o arsenal de conceitos utilizados, contribuindo assim para o debate. Alguns trabalhos recentes já percorrem esses caminhos.

Silvia Brügger, por exemplo, parte da noção de patriarcalismo como um conjunto de valores e práticas que colocam a família no centro da ação social, aplicando-o à sua análise sobre a sociedade mineira ${ }^{28}$.

Cacilda Machado, por sua vez, parte do princípio de que a apropriação do patriarcalismo de Freyre apenas como um conjunto de valores e práticas que colocam a família no centro da ação social, ou como um ideal disciplinador, não é útil para a ampliação do conhecimento. A autora utiliza a noção de família patriarcal de maneira diferente, procurando encontrar o caráter patriarcal das relações estabelecidas entre homens e mulheres livres, fora do contexto da grande propriedade escravista, numa área onde predominava o trabalho familiar ${ }^{29}$.

Por conta de todo esse debate, entendemos por que as discussões relativas à família não podem limitar-se a uma análise da componente demográfica ou variável relativa à corresidência. Elas não dão conta da complexidade do universo da família que tece teias que vão além dos limites dos vínculos biológicos primários e da convivência sob o mesmo teto. E essa perspectiva renovou o interesse dos historiadores - influenciados pelos estudos microanalíticos - pelo estudo da família, apostando não só na análise das trajetórias individuais e familiares, mas também apostando na utilização de conceitos como rede social ou estratégia familiar, como salientamos no início desse artigo.

27 BARICKMAN, op. cit., p. 122-130.

28 BRÜGGER, op. cit.

29 Veja artigo e livro citados anteriormente (MACHADO, 2006, 2008). 
Diversos são os trabalhos publicados recentemente que têm investido nessa linha interpretativa, buscando analisar a dinâmica familiar da nossa sociedade tendo a noção de patriarcalismo como aspecto central para a compreensão do tema. O estudo das redes sociais, nesta perspectiva analítica, tem enorme utilidade para o pesquisador e tem aberto caminhos profícuos na última década para a compreensão da sociedade brasileira, tanto na época colonial como ao longo do período imperial. A questão do poder assume, nesse contexto, papel fundamental em muitos desses trabalhos.

Em que pesem as transformações que marcaram a sociedade brasileira, desde o período colonial até o final do século XIX, não é possível deixar de notar que a família continuou a exercer papel central não só entre os grupos mais privilegiados, como também entre os segmentos menos favorecidos. Estão aí os trabalhos já clássicos de Hebe Maria Mattos, que recolocam a questão do conceito de patriarcalismo ao analisar o sudeste brasileiro no século XIX, ou o estudo mais recente de Cacilda Machado, que mostra a necessidade de se dar respostas às questões suscitadas pelas pesquisas demográficas sobre a história da família livre ou escrava, de se debruçar sobre os significados culturais das "associações familiares" na sociedade escravista e em seu papel central no estabelecimento das hierarquias e relações sociais.

Não é possível pensar o patriarcalismo limitado à configuração do domicílio extenso, mas como um pressuposto fundamental para entender a importância dos "laços familiares", entendidos de uma maneira mais elástica e construídos não só a partir do parentesco biológico, mas através dos laços baseados nas alianças matrimoniais, nas relações de compadrio e na "economia do dom", que funciona através da lógica dos atos de dar e retribuir, constituindo relações de "amizade desigual" que as diferentes esferas de poder legitimavam ${ }^{30}$.

Nesta lógica familiar, estavam em primeiro lugar os interesses coletivos do grupo, da parentela, dos que faziam parte e estavam integrados no círculo de "amigos" e dependentes. Compreender as diferentes tramas que ligavam indivíduos e famílias de distintas posições sociais, neste universo heterogêneo que é o Brasil escravista, passou a ser o grande desafio dos historiadores da família.

30 Para aprofundar essa temática é essencial recorrer a Marcel Mauss, sobretudo no texto "Ensaio sobre a dádiva - forma e razão da troca nas sociedades arcaicas", in: Sociologia e Antropologia. São Paulo: Cosac \& Naify, 2003. 
É relevante ressaltar também que nos trabalhos mais recentes persistem duas características comuns à maioria das pesquisas relativas à história da família. Em primeiro lugar, a utilização de um conjunto diversificado de fontes, que vão desde as mais comumente utilizadas, como os registros paroquiais e listas de população, passando pelos testamentos, inventários post-mortem, processos-crimes, documentação inquisitorial, cartas, diários, escrituras de dote, de compra e venda de escravos, fotografias, entre outras. Em segundo lugar, do ponto de vista das metodologias, há uma predileção pela microanálise, pelo cruzamento de fontes, pelos seguimentos nominativos que dão a tônica dos trabalhos mais recentes, que analisam as mais diferentes regiões do país, do Pará ao Rio Grande do Sul, assim como os diferentes grupos sociais. De sul a norte, e apenas para citar os estudos mais recentes, temos aqueles relativos ao Rio Grande do Sul, a maioria constituída de teses de doutorado e dissertações de mestrado ainda não publicadas, como as de Fábio Kühn, Martha Hameister, Luis Augusto E. Farinatti, Jonas M. Vargas e Bruna Sirtori ${ }^{31}$. Cacilda Machado, por sua vez, apresenta um estudo sobre São José dos Pinhais, no atual Estado do Paraná. Para o Rio de Janeiro, o belo trabalho de Mariana Muaze. Para Minas Gerais, entre tantos trabalhos, temos os estudos de Silvia Maria J. Brügger e de Renato Pinto Venâncio. Para o nordeste, o estudo de Antonio Otaviano Vieira Júnior sobre o Ceará ${ }^{32}$.

Estes são exemplos bastante ilustrativos dos caminhos trilhados pela história da família no Brasil.

31 Veja: KÜHN, F. Gente da fronteira: família, sociedade e poder no Sul da América Portuguesa - século XVIII. Tese (Doutorado) - Programa de Pós-Graduação em História, Universidade Federal Fluminense, Niterói, 2006; HAMEISTER, M. D. Para dar calor à nova povoação: estudo sobre estratégias sociais e familiares a partir dos registros batismais da vila do Rio Grande (1738-1763). Tese (Doutorado) - Depto. de História, Universidade Federal do Rio de Janeiro, Rio de Janeiro, 2006; FARINATTI, L. A. E. Confins meridionais: famílias de elite e sociedade agrária na fronteira sul do Brasil (1825-1865). Tese (Doutorado) - Depto. de História, Universidade Federal do Rio de Janeiro, Rio de Janeiro, 2007; VARGAS, J. M. Entre a Paróquia e a Corte: uma análise da elite política do Rio Grande do Sul (1868-1889). Dissertação (Mestrado) - Programa de Pós-Graduação em História, Universidade Federal do Rio Grande do Sul, Porto Alegre, 2007; SIRTORI, B. Entre a cruz, a espada, a senzala e a aldeia. Hierarquias sociais em uma área periférica do Antigo Regime (1765-1784). Dissertação (Mestrado) - Depto. de História, Universidade Federal do Rio de Janeiro, Rio de Janeiro, 2008.

32 MACHADO, Cacilda. Op. cit., 2008. MUAZE, M. As memórias da Viscondessa. Família e poder no Brasil Império. Rio de Janeiro: Zahar, 2008; BRÜGGER, S. M. J. Minas patriarcal: família e sociedade. São Paulo: Annablume, 2007; VENÂNCIO, R. P.; SOUSA, M. J. F. D. et al. O Compadre Governador: redes de compadrio em Vila Rica de fins do século XVIII. Revista Brasileira de História, v. 26, n. 52, p. 273-294, 2006; VIEIRA Jr., A. O. A inquisição e o sertão. Fortaleza: Edições Demócrito Rocha, 2008. 
Vale notar ainda que, apesar da utilização dessa gama variada de fontes de cunho quantitativo e qualitativo, os registros paroquiais continuam ocupando lugar privilegiado para ajudar os historiadores a desvendarem e compreenderem as teias tecidas pelas famílias no universo do Brasil escravista. Um bom número de estudos explora o tema do compadrio, por meio do estudo dos assentos de batismo, janela privilegiada para chegar ao âmago das redes sociais construídas pelas populações no passado.

Como tem sido frisado, o batismo era o sacramento mais difundido entre a nossa população e, a partir daí, os pesquisadores procuram explorar a importância da escolha dos padrinhos e que estratégias e mecanismos estavam por trás da preferência. Quase todos os trabalhos citados analisaram a questão do compadrio, este parentesco ritual que institui alianças sociais não só entre indivíduos do mesmo estatuto, como também abre possibilidade de se escolher indivíduos de condição diferente da dos pais da criança.

O compadrio tem sido amplamente estudado e as pesquisas abrangem os segmentos livre e escravo da população. Embora o estudo do compadrio esteja muito disseminado, Renato Venâncio pondera que a análise da escolha dos padrinhos no período colonial quase sempre se restringia à população escrava. As investigações sobre compadrio na população livre são mais raras.

Procurando contribuir para o debate, por meio do estudo do compadrio entre a elite mineira colonial, parte, como a maioria dos autores, da hipótese de que na sociedade da época a noção de "prestígio" vinculava-se à capacidade de dispor de recursos (fossem eles pessoais ou do aparelho de Estado), gerando assim uma "economia de favores", de dom e contradom, em outras palavras, de reciprocidade social envolvendo desiguais. Ao benfeitor cabia conceder e ao beneficiado ser fiel, não sendo esse gesto visto como um desvio da "norma", mas sim como sua corporificação.

Nesse sentido, a noção de "amizade desigual", que subordinava a reciprocidade ao respeito e à hierarquia social, tornava-se o elemento legitimador das relações de poder internas ou externas aos grupos sociais. No caso do compadrio, tais vínculos eram ainda mais intensos, pois geravam laços de parentesco para o resto da vida - tanto na relação padrinho-afilhado quanto na de compadre-compadre. Nesse sentido, é possível afirmar que o compadrio consistia em um dos elementos de estruturação das redes sociais que organizavam a vida cotidiana. 
Silvia Brügger, em seu livro Minas Patriarcal (2007), dedica todo um capítulo à questão do compadrio, ao analisar o caso de São João del-Rei entre os séculos XVIII e XIX. Afirma que os padrinhos escolhidos para as crianças em sua esmagadora maioria eram de condição igual ou superior à da mãe e que, ao longo de todo o período, foram raros os filhos de mães livres que tiveram padrinhos forros ou escravos.

Cacilda Machado (2008), assim como Brügger, também dedica um capítulo de seu livro para o estudo do compadrio, dando ênfase às alianças sociais entre escravos, negros e pardos livres, e verifica que o parentesco espiritual era utilizado tanto como estratégia para criar laços com pessoas de estatutos sociais superiores para obter proteção, como também poderia funcionar como meio de socialização de modo a formar uma comunidade de escravos e livres pobres.

Fábio Kühn e Martha Hameister também enveredam pelos mesmos caminhos para analisar o compadrio e as redes que se formaram entre os indivíduos e grupos familiares na porção meridional da colônia, no século XVIII.

Por outro lado, outras perspectivas são exploradas pelos historiadores da família, aproveitando fontes de outra natureza, mas que se mostraram extremamente fecundas e enriqueceram as leituras possíveis sobre o universo familiar.

Destacam-se dois trabalhos que analisam períodos e regiões diferentes, mas que em comum oferecem um olhar instigante sobre a família, através de uma narrativa que flui de maneira muito agradável.

O primeiro leva o leitor a perceber as possibilidades de pesquisa para a história da família por meio da exploração das fontes inquisitoriais (habilitação de familiares do Santo Ofício), denúncias e processos depositados no Arquivo Nacional da Torre do Tombo (Lisboa) e adentrar na intimidade da trajetória de indivíduos e famílias muito diferentes, de livres e de escravos, de ricos e de pobres, enredados nas teias do Santo Ofício e que viveram no Ceará setecentista.

O segundo, por sua vez, leva-nos à região de Vassouras, Rio de Janeiro, no século XIX. Diferentemente da maioria dos trabalhos relativos à história da família no Brasil, sua análise foi construída a partir de documentos privados - cartas, diários, livros de assento, cadernos de anotações e fotografias -, revelando ao leitor o mundo das famílias abastadas do 
Império. O resultado foi uma entrada, sem cerimônia e com muita habilidade e desenvoltura, na intimidade e no cotidiano da nobreza imperial, no universo da família e do poder entre barões, viscondes e viscondessas. A autora conseguiu redesenhar as redes de solidariedade e mecanismos de sobrevivência que permitiram a manutenção de certos grupos entre o restrito círculo dominante na sociedade imperial.

Em poucas palavras, esses trabalhos indicam alguns dos caminhos mais promissores que os historiadores da família vêm trilhando, apresentando uma perspectiva muito diferente daquela que predominou ao longo das décadas de 1980 e 1990. Os estudos mais recentes apostam na aplicação de fontes e metodologias variadas, na ampliação e no aprofundamento da análise conceitual, e procuram fugir do eixo temporal e geográfico que havia predominado anteriormente.

Estas reflexões podem perfeitamente encerrar-se parafraseando a opinião expressa por Mariana Muaze, que faz uma avaliação interessante sobre as diferentes maneiras que o tema da família foi tratado pela historiografia. Para a autora, seja pensando a sua relação com o Estado ou articuladas ao movimento de busca de novos objetos - intenções que, a princípio, podem ter sido diferentes -, estas perspectivas de estudo não são excludentes. É possível que elas possam andar juntas quando se altera a escala de observação histórica. Isto é, o estudo das trajetórias individuais e das estratégias familiares pode oferecer outra chave de compreensão sobre esse tema fundamental para a historiografia brasileira, quando procuramos desatar os "nós" das teias que são tecidas pela família.

Recebido em maio de 2009. Aprovado em maio de 2009. 